\title{
Imposter Syndrome and Self-Deception
}

\author{
Stephen Gadsby
}

This is a preprint of an article whose final and definitive form will be/is published in the Australasian Journal of Philosophy. The Australasian Journal of Philosophy is available online at: http://www.tandf.co.uk/journals/.

\begin{abstract}
Many intelligent, capable, and successful individuals believe that their success is due to luck and fear that they will someday be exposed as imposters. A puzzling feature of this phenomenon, commonly referred to as imposter syndrome, is that these same individuals treat evidence in ways that maintain their false beliefs and debilitating fears: they ignore and misattribute evidence of their own abilities, while readily accepting evidence in favour of their inadequacy. I propose a novel account of imposter syndrome as an instance of self-deception, whereby biased evidence treatment is driven by the motivational benefit of negative self-appraisal. This account illuminates a number of interconnected philosophical and scientific puzzles related to the explanation, definition, and value of imposter syndrome.
\end{abstract}

\section{Keywords}

imposter syndrome; imposter phenomenon; self-deception; rationality; motivated belief; belief-based utility 


\section{What is Imposter Syndrome?}

Sarah is a philosophy student in a highly ranked $\mathrm{PhD}$ program, supervised by a wellregarded professor. She received excellent grades throughout her undergraduate degree, which, along with glowing references from her teachers, earned her a spot in the prestigious program. Sarah's supervisor regularly praises her work, and audience members respond positively to her talks. Despite this, Sarah considers herself to be less intelligent than the other graduate students. While they clearly have what it takes to be in the program and move on to permanent positions, Sarah believes her current success is largely due to luck.

This situation causes significant mental anguish for Sarah, who fears her inadequacy will be exposed. Sarah works incredibly hard, obsessing over the minor details of her written prose and presentation style. Sarah will not be convinced of her own merit. In receiving written feedback from her supervisor, she hurriedly skims the positive comments, seeking out the few that indicate shortfalls. While reflecting on the feedback she has received on her presentations, Sarah remembers few of the (mostly) positive comments but can vividly recall the tone of a derisive audience member who rebutted her during question time, many months ago.

The above vignette may strike readers as familiar. Perhaps you recognise this behaviour in someone you know; perhaps you even recognise it in yourself. This constellation of behaviours and attitudes is referred to colloquially as imposter syndrome, a widely 
observed phenomenon affecting individuals from all walks of life-most notably, college students and career academics [Langford and Clance 1993].

There is much we do not know about imposter syndrome. Although the concept was introduced in the 70s [Clance and Imes, 1978], it has struggled to attract scientific attention [Bravata et al. 2019], and, up until recently, has escaped the interest of philosophers [Hawley 2019a, 2019b; Paul 2019; Slank 2019]. Nevertheless, there are a number of intriguing and important philosophical issues related to the phenomenon.

First and foremost, the condition is epistemically puzzling: why does Sarah engage in faulty reasoning concerning her own abilities, especially when it causes her such mental anguish? Imposter syndrome appears to undermine the assumption that humans are, by and large, epistemically and pragmatically rational—that we reason in ways which track truth and promote well-being [Bortolotti 2014]. We are thus faced with the task of explaining why people with imposter syndrome deviate so significantly from these norms of rationality.

There are also definitional issues to resolve. Philosophers have made an excellent start on outlining potential necessary and sufficient conditions for imposter syndrome [Hawley 2019b; Paul 2019] and drawing parallels between imposter syndrome and other apparent instances of irrationality [Hawley 2019a], yet there is still much to be done. For example, an outstanding question is how to categorise the phenomenon: among the myriad of known mental states, traits, and maladies, where does it fit?

Finally, there is the issue of value. Among scientists and philosophers, the condition is seen as overwhelmingly negative. Yet none have questioned whether imposter syndrome might provide some value to those who exhibit it. 
In this paper, I will make progress on the task of explaining, defining, and evaluating imposter syndrome. I will provide a novel account of the phenomenon, whereby people with imposter syndrome are motivated to downplay their own ability due to the motivational benefits of doing so. Consequently, imposter syndrome qualifies as an instance of self-deception. A corollary of this position is that imposter syndrome cannot be understood without considering the value it holds for some individuals.

To be clear, I do not intend to provide an account of imposter syndrome that is true for all those who exhibit it. One point of consensus from the scientific literature is that the category of imposter syndrome is heterogeneous: different individuals exhibit it for different reasons—-psychological, developmental, and socio-cultural—and for any particular individual, their condition may need to be explained with reference to multiple factors [Clance and Imes 1978; Harvey and Katz 1985; Sakulku and Alexander 2011; Leonhardt et al. 2017]. I will simply argue that, within the concept of imposter syndrome, we must make room for a self-deceptive variant.

\section{Defining Imposter Syndrome}

Imposter syndrome is not a syndrome in the common sense of the term: it involves neither disease nor disorder [Clance 1985: 23]. Clance and Imes [1978] were careful in giving it the more neutral label 'imposter phenomenon', to avoid this association. To have imposter syndrome is simply to exhibit a set of related emotions, attitudes, and behaviours. Here, following the most common definition in the psychological literature, I assume imposter syndrome to involve three features: affective, doxastic, and behavioural [Harvey and Katz 1985]. 


\subsection{The Affective and Doxastic Features}

The affective feature involves a fear of being discovered and exposed as an imposter-one who does not belong in the role they occupy and does not deserve the success they achieve. As Leonhardt et al. [2017: 7] describe, 'these individuals describe their greatest fear as being exposed as incompetent, less intelligent and thus as a phony'. This fear leads to a host of negative psychological consequences, such as anxiety, stress, and emotional exhaustion [ibid.].

Fear of being discovered is related to the doxastic feature of the condition, standardly characterised as a belief in one's own inadequacy [Clark et al. 2014]. Specifically, those who suffer from imposter syndrome believe that they lack ability. Such beliefs are not only false- they are just as, if not more able than their peers-but unjustified, as people with imposter syndrome are exposed to significant evidence in favour of their own ability (see below).

A crucial point to note is that people with imposter syndrome do not hold negative beliefs regarding all their role-relevant attributes. Many believe that they are charming, personable and, importantly, that they are hard workers [Hawley 2019b: 205]. Thus, imposter syndrome is not a case of domain general negative self-evaluationinadequacy beliefs only relate to certain kinds of abilities (see section 5.2). Commonlyespecially in the academic context—inadequacy beliefs refer to lacking intelligence, but the relevant properties can vary between different contexts and cases. For example, in her 
first-person account of imposter syndrome, Olberding [2018] describes believing that she 'lacked the standard cultural and class equipage of academe'.

Some discussions of these inadequacy beliefs assume that they refer to 'innate' or 'fixed' abilities [Kumar and Jagacinski 2006; Paul 2019; Slank 2019]. While this is true much of the time, a better specification is that the abilities are difficult to come by. Cultural equipage is not innate or fixed, but it is difficult to come by without a particular kind of upbringing.

\subsection{The Behavioural Feature}

People with imposter syndrome are exposed to significant evidence in favour of their abilities; positive test scores, awards, accolades from colleagues and, of course, the simple fact that they are in the position they are in (while others are not) all speak to the fact that they are suitably able. The most puzzling feature of the condition is why this evidence fails to exert the epistemic effect one would expect. The answer to this puzzle lies in the behavioural feature of imposter syndrome.

Imposter syndrome is defined by a range of biases in the treatment of evidence related to the individual's abilities: 'Imposters ... dismiss praise, derogate the accuracy of positive evaluations, and engage in other behaviors that insulate them against information that would validate their competence and worth’ [Leary et al. 2000: 727]. The most notable of these biases pertains to the interpretation of evidence; Sarah regularly misattributes her own success, as do others with imposter syndrome:

\footnotetext{
${ }^{1}$ Precisely what cultural and class equipage entails is difficult to pin down; it seems to point to a constellation of properties, such as the way one speaks (e.g. their accent and vocabulary), the clothes they wear, and the knowledge they hold (e.g. who composed an 'Ode to Joy') [ibid.].
} 
They attributed their successes to hard work, luck, knowing the right people, being in the right place at the right time, or to their interpersonal assets such as charm and the ability to relate well, rather than to ability or competence ... These subjects were ingenious at negating objective external evidence that indicated they were indeed very bright. [Clance and OToole 1987: 52]

Negative interpretation of success is accompanied by an inordinate focus on, and acceptance of, markers of failure. [ibid.].

On the standard account of imposter syndrome, explaining biased evidence treatment is crucial to explaining the condition. Fear of being exposed as an imposter stems from an unjustified belief in inadequacy, and this unjustified belief is adopted and maintained due to a biased treatment of the available evidence. To explain imposter syndrome, then, we must explain this behavioural feature.

\section{Self-Deception}

I will argue that some instances of imposter syndrome ought to be classified as selfdeception. What is self-deception? Consider a common example:

Jessica's teenage son has begun to act strangely. He comes home late at night with bloodshot eyes, smelling of marijuana. Despite evidence that her son may be smoking marijuana, Jessica will not accept it. She brushes off her husband's 
attempts to convince her of the truth. Upon finding various paraphernalia in his room, she concludes that it must have been left by a friend.

A key feature of self-deception is present in this example: biased treatment of the available evidence. In brushing off her husband's arguments and explaining away the paraphernalia, Jessica is contributing to the maintenance of her own false belief. According to the standard understanding of self-deception, Jessica's own desire for her son to be drug-free causes her to engage in these biased practises.

Consider another variant of self-deception:

Chris loves his wife but believes she is having an affair. Although she has excellent work-related reasons for coming home late occasionally and no prior record of infidelity, Chris takes his wife working late as evidence of an affair. He carefully attends to her social plans, interpreting slightly anomalous events as planned rendezvous with her lover.

Here the standard understanding falls apart; Chris does not desire that his wife is having an affair, in fact he desires the opposite. Philosophers refer to this kind of self-deception as twisted [Mele 2001], dreadful [Van Leeuwen 2007], and negative [Funkhouser 2019], and there is a broad consensus that a complete account of self-deception ought to accommodate both these forms [Funkhouser 2019; Mele 2001]. I will argue that Chris and Sarah are alike in that they both suffer from twisted self-deception.

\subsection{Defining Self-Deception}


Here, I assume a definition of self-deception as involving three conditions [Mele 2001: 120]. First, the self-deceived believe a proposition that is unwarranted by the available evidence. ${ }^{23}$ Second, this unwarranted belief is maintained through biased evidence treatment. This comes in many different forms [Funkhouser 2019: 116], the most common of which relate to: search—seeking out supporting (and avoiding contradictory) evidence; sampling:- - selectively attending to and recalling from memory supporting evidence; and interpretation—-positively interpreting supporting evidence, while rationalising away contradictory evidence.

People with imposter syndrome satisfy both of these conditions: they believe in their own inadequacy (despite this belief being unwarranted by the available evidence) and they maintain this belief through biased evidence treatment, most notably, biased interpretation. Whether imposter syndrome qualifies as self-deception depends on it satisfying a third condition, related to the cause of these biases. Specifically, selfdeception requires that the relevant biases are motivated, i.e. driven by desires, emotions, or incentives of some form [Funkhouser 2019: 14].

One philosophically vexed aspect of self-deception involves characterising the precise form of motivational bias at play. Accounts of self-deception are divided into two broad camps over the issue: intentionalists and motivationalists. Modelling their accounts

\footnotetext{
2 Note that 'available evidence' refers not to the evidence an individual possesses, but to the evidence that is 'easily available' to them [Lynch 2012: 441]. This ensures that those who possess belief warranting evidence in virtue of their biased evidence gathering (e.g. actively seeking out supporting evidence) may still qualify.

${ }^{3}$ I put aside the requirement that those who are self-deceived engage in behaviour that suggests that, at some level, they are aware that the relevant belief is false [Schwitzgebel 2002]. Philosophers generally accept that there are some cases of self-deception where the self-deceived show all the markers of belief in the proposition, with no indication that they believe the opposite [Mele 2001; Lynch 2012; Funkhouser 2019]. Thus, I will focus on this more straightforward notion of self-deception.
} 
on interpersonal forms of deception, intentionalists claim that the self-deceived intentionally deceive themselves [Bermúdez 2000]. In contrast, motivationalists claim that while self-deception is motivationally driven, it is unintentional [Mele 2001]. I will address these differences in section 5.4 .

\section{Belief-Based Utility and Evidence Treatment}

In this paper, I will draw heavily from an account of self-deception from the economics literature, a guiding assumption of which is that 'people derive utility not only from possessions and experiences, but also from beliefs' [Golman et al. 2017: 128]. In their work, Bénabou and Tirole [2016] emphasize two categories of this belief-based utility. The first category is affective: beliefs about ourselves and our prospects have a 'direct and powerful affective impact' [ibid.: 143]. Seeing ourselves and our prospects in a positive light is satisfying (utility), while seeing ourselves and our prospects in a negative light causes sadness and worry (disutility). The second category is motivational: 'confidence in one's ability and chances of success [or those of teammates] can be a powerful motivator to pursue difficult long-term goals and persevere through adversity’ [Bénabou 2015: 6]. For example, the belief that one is almost at the end of a difficult task motivates oneself to persevere.

What are the effects of belief-based utility? Crucially, they are not direct: we do not simply revise our beliefs on consideration of the relevant utility. Instead, belief-based utility biases our evidence treatment practises - in the realms of evidence search, sampling, and interpretation—such that our (future) selves are guided towards beliefs with higher utility [Brocas and Carrillo 2000; Sharot and Sunstein 2020]. According to 
this framework, the biased evidence treatment associated with self-deception stems from attempts to maximize belief-based utility.

Consider how this framework applies to the aforementioned examples of selfdeception. We can explain Jessica's behaviour by assuming that she is biased away from the affective disutility (anxiety) associated with believing her beloved son is smoking marijuana [see Barnes 1997]. In the case of Chris, believing that his wife is unfaithful may be perceived as providing a certain motivational utility. As Mele (borrowing from Pears [1984]) puts it:

the value of his jealousy-inspired belief in his wife's infidelity lies in its capacity in combination with his desire for her fidelity, to lead him to take steps to reduce the chance that she will have affairs by, for example, increasing his vigilance [2001: 95].

This excessive vigilance may be perceived as necessary to maintain or control the relationship, even though (paradoxically) it may drive the wife away [ibid.: 101]. It is important to note that economic accounts of self-deception do not assume that the self-deceived are aware of these biases. Indeed, as Bénabou and Tirole write: ... the process of manipulating one's own attention, memory, or awareness must not be too transparent. There must be some opaqueness as to what exactly one is failing to update to, some ambiguity as to why certain actions are taken or not taken [2016: 147]. 
This framework is thus consistent with recent accounts of self-deception that argue for the empirical plausibility (and importance) of unconscious self-deceptive processes [Funkhouser and Barrett 2016].

\section{Imposter Syndrome: Maladaptive or Motivational?}

Some psychologists suggest that imposter syndrome stems from problematic parenting styles or family dynamics. As Langford and Clance [1993: 497] write, 'people who experience impostor feelings are likely to come from families in which support for the individual is lacking, communications and behaviors are controlled by rules, and considerable conflict is present' (see also Clance and Imes [1978] and Thompson [2004]). Accordingly, 'To truly understand the Impostor Phenomenon... it's essential to start at the beginning — with the Impostor's family' [Clance 1985: 465]. On these accounts, imposter syndrome is neither intentional nor motivated, as those who exhibit it are simply acting out maladaptive reasoning styles that were internalised during childhood [ibid.: 55-62]. In contrast, I argue that imposter syndrome, in many cases, is driven by the benefits of believing in one's own inadequacy. In order to understand this form of imposter syndrome, we must consider the utility of inadequacy beliefs, along with the factors (psychological and situational) that determine that utility.

Consider the utility associated with believing that one lacks ability, as individuals with imposter syndrome do. There is obvious disutility involved, in terms of the negative affect that stems from such a belief. As Bénabou and Tirole [2016: 143] note, holding negative beliefs about ourselves (that we lack ability) and our prospects (that we are likely to fail) causes distress and anxiety. Thus, all things being equal, we should be biased away 
from such beliefs. This is precisely what the psychological literature suggests, as there is a general tendency towards positive evaluation of own abilities [Taylor and Brown 1988]

In the case of imposter syndrome, this negative utility is especially potent. People with imposter syndrome do not simply believe that they lack ability, they believe that they lack the ability that is crucial for succeeding in a greatly valued role. Not only do they suffer from this belief, they suffer from the resulting fear of their inadequacy being discovered and exposed. When considered in light of affective disutility, the biased evidence treatment associated with imposter syndrome appears maladaptive, undermining these individuals' own basic desire for happiness. When faced with explaining behavioural patterns that work against someone's own interests, psychologists commonly look to their history. Thus, it is unsurprising that many psychologists have assumed a relationship between imposter syndrome and childhood experiences.

In contrast to these accounts, I argue that there is an overlooked benefit of the condition. Specifically, I argue that beliefs in low ability bestow a motivational benefit, one which is particularly attractive for those who wish to succeed in contexts where the pathway to success is both challenging and opaque. In what follows, I discuss a number of preconditions that (jointly) cause a belief in low ability to provide high motivational utility. First, the individual strongly desires to succeed — this ensures that any belief that aids in succeeding will provide high utility. Second, the individual believes that the domain is one where significant effort is required to succeed-this ensures that beliefs that motivate effort have high utility. Third, the domain is one where the individual believes that effort can substitute ability, such that a belief that one lacks ability will have motivating (rather than demotivating) effect. Finally, the domain is one where accurate belief provides low utility, rendering self-deception more advantageous. 
As I will show, these conditions are commonly found in contexts where imposter syndrome thrives. Following the emphasis in the scientific literature, I will illustrate my point by focusing on the academic context. Nevertheless, I contend that such conditions will hold in other contexts where imposter syndrome is commonly found.

\subsection{Desire for Success where Effort is Necessary}

The first precondition is that people with self-deceptive imposter syndrome strongly desire to succeed. This claim is uncontroversial. Descriptions of imposter syndrome from the scientific literature regularly describe these individuals' 'strong desire ... to be the very best among their peers' [Schubert and Bowker 2019: 749]. The presence of such a desire is also consistent with evidence that imposter syndrome highly correlates with success driven traits such as fear of failure and perfectionism [Clance and OToole 1987; Kumar and Jagacinski 2006; Sakulku and Alexander 2011].

The second precondition is that people with self-deceptive imposter syndrome believe that, natural abilities notwithstanding, succeeding requires significant effort. This ensures that beliefs that motivate effort will provide high utility. Significant effort is necessary in contexts where competition is high and succeeding is difficult, such as those where imposter syndrome is commonly found. Consider the context of academia. Succeeding in this domain is exceedingly difficult: research suggests that only $3.5 \%$ of $\mathrm{PhD}$ students secure a permanent position at a university and, of those, only $12 \%$ become professors [Taylor et al 2010: 14]. This ensures that even those who are bright and talented do not succeed. In challenging domains such as these, substantial effort is required, which people with self-deceptive imposter syndrome are aware of. 


\subsection{Effort and Ability are Substitutes}

The third precondition is the belief that effort can substitute ability. Bénabou and Tirole [2002: 873] point out that, in most contexts, ability and effort are complementary: they combine multiplicatively to determine outcomes. Due to this, belief in our own ability has a positive motivational effect. In scenarios where ability and effort are complementary, if one believed that they had little or no ability, then even a significant amount of effort would provide them with little return. If I believe that I am entirely hopeless at chess then_fearing a short, embarrassing, and unfulfilling game-I may not bother playing at all. Believing that I am somewhat capable will prompt me to play, under the assumption that, with a bit of effort, I may win (or at least give my competitor a run for their money). Thus, in many cases, positive belief in one's own abilities is motivational. Because positive beliefs in ability provide this utility, we are biased towards such beliefs.

Nevertheless, in some contexts, negative self-appraisal has a positive motivational effect:

A student preparing for exams may ... discount his previous good grades as attributable to luck or lack of difficulty. A young researcher may understate the value of his prior achievements, compared with what will be required to obtain tenure. A dieting person who lost a moderate amount of weight may decide that he 'looks fatter than ever,' no matter what others or the scale may say. [Bénabou and Tirole 2002: 904] 
In such scenarios, we exaggerate the difficulty of the task at hand in order to steer our (future) selves away from 'coasting' or 'slacking off'. This phenomenon appears in a number of different contexts. For example, Norem and Cantor provide evidence that when facing tasks with a high possibility of failure, many students dwell on how unprepared they are 'in order to get [themselves] to work harder' [1986: 1213]. Similarly, evidence suggests that people with eating disorders visually attend to the parts of their bodies that appear 'fatter', in order to motivate their own dietary restraint [Gadsby 2020: 616].

In certain contexts, negative self-appraisal provides motivational utility by signalling to ourselves the need for effort. When negative self-appraisal is related to ability, motivational benefit will only occur if the individual believes that ability and effort are potential substitutes [Bénabou and Tirole 2016: 145]. When we believe that effort can substitute ability, negative appraisal of our own ability can be motivationally beneficial. There is good reason to think that people with imposter syndrome believe that this is possible. After all, they expend incredible energy towards achieving their goals, despite believing that they lack ability. In fact, such effort is assumed to result from these beliefs [Yaffe 2020: 1]. ${ }^{5}$ This intense diligence and hard work also pays off, in terms of 'excellent performance and approval from authorities', precisely the forms of compensation required to succeed [Clance and Imes 1978: 244].

\footnotetext{
${ }^{4}$ For example, this condition often holds in domains where the rewards are of a pass-fail nature, such as 'graduating from school, making a sale, being hired or fired (tenure, partnership), proposing marriage, etc.' [Bénabou and 'Tirole 2002: 905]. As anyone who has underachieved throughout high school will recognise, believing you are terrible at a subject but needing to pass it in order to graduate is a wonderful motivator to study.

${ }^{5}$ In fact, some psychologists suggest the motivational effect of inadequacy beliefs is two-fold: first, people with imposter syndrome work harder to overcome their lack of ability; second, they work harder so as not to have their lack of ability discovered [Clance and Imes 1978: 244].
} 
Such effort cannot be explained solely through reference to a desire for success.

Desire does not drive effort when one believes that they lack the necessary ability, and that ability cannot be substituted with effort. No matter how strongly I desire to be a fashion model, I know that I am simply not blessed with the right genetics—no amount of make-up, hair styling, or gruelling gym sessions are going to make up for that fact. I do not bother with these activities because I know they cannot make up for my genetic shortfalls. This explains why, despite believing that they lack ability, people with imposter syndrome do not simply give up; those who believe that they lack ability, but that they can make up for it with effort, persist in pursuing their goals.

While those with imposter syndrome believe that they lack attributes that would make succeeding easier — intelligence, brilliance, talent, cultural equipage — they do not hold negative beliefs about all their abilities: they commonly believe themselves to be hard workers [Hawley 2019b: 205]. Believing that they did not possess the capacity to work hard would undermine the motivational benefit of believing that the task at hand is difficult to achieve. This helps to define the inadequacy beliefs associated with selfdeceptive imposter syndrome: those who exhibit it believe that they lack the kinds of abilities that can be substituted for effort.

\subsection{Accurate Knowledge of Ability Provides Low Utility}

The final precondition for self-deceptive imposter syndrome is that accurate knowledge of one's own abilities provides low utility. In most contexts, accurate knowledge of our own abilities is useful for achieving our goals because it aids in planning. If my goal is to make it into the local basketball team, then an accurate assessment of my basketball skills 
will help. For example, if I know that my offensive game is unparalleled, but that I cannot shoot free throws, then I know what I need to work on. I can focus my efforts on improving my free throw ability, up to a level at which the local team will allow me to join. I will not waste resources (time and effort) practising offensive skills, because I know this strategy will not pay off.

However, in some domains, accurate knowledge of our own abilities is not so useful. This is the case when the pathway to success is particularly opaque. Consider again the academic context. What it takes to succeed in this domain is overwhelmingly difficult to discern, as is evident in the following anecdote from a junior academic:

I visited the university's HR advisor and asked her - naively - what I would have to do to eventually be appointed professor. Her answer was frank: 'I have no idea.' My group leader, a professor, couldn't help either and told me that 'there is no clearly defined path that will get you there'. The university agreed to investigate the issue, and later introduced a set of criteria to define what was expected of academics at different levels. But those criteria were set so high that it was impossible for anybody to achieve them - including the professors themselves. [Anonymous Academic 2018]

One might respond that, while there may not be a precisely laid out pathway to success in academia, most academics still possess a (rough) idea of what is required: publication in top journals, citations, respect from colleagues, and the like. The important point, however, is that it is unclear which specific activities one should dedicate their time to in 
order to reap such benefits_-if it were otherwise, our hard drives and notebooks would not be so full of half-finished projects and abandoned ideas.

While in most scenarios, accurate knowledge of one's own abilities is useful for planning, this is only the case when the necessary actions are known (if I know what I need to do, I know whether it is the kind of thing I am capable of). In situations where the pathway to success is opaque, accurate knowledge of one's own abilities does not confer this advantage; even perfect self-knowledge cannot overcome not knowing what needs to be done. This point is crucial. As economic models of self-deception stress, when there is no utility provided by being accurate, alternative forms of utility play a stronger role in biasing evidence treatment [Brunnermeier and Parker 2005]. ${ }^{6}$

\subsection{Summary}

Self-deceptive imposter syndrome involves a strong desire to succeed in a domain that requires great effort and where the pathway to success is opaque. This ensures that people are willing to exert significant effort to succeed and, given the difficulty of succeeding, this is precisely what is required. It also ensures that accurate self-knowledge is less useful for achieving this goal, as it does not aid in planning. In these domains, those who believe that ability can be substituted with effort derive a motivational benefit from believing that they lack ability. For such individuals, this additional motivation is regarded as significantly beneficial, as it brings them closer to the success they so strongly

\footnotetext{
${ }^{6}$ Of course, this does not entail that knowledge of one's own abilities provides no utility whatsoever, it may provide many sources of utility (for example, when it is positive, it will entail positive affect). The important point, however, is that in contexts where imposter syndrome is found, accurate knowledge of one's own abilities does not make succeeding easier.
} 
desire. For individuals who satisfy these conditions, the motivational utility of a belief in lacking ability will outweigh its affective disutility. According to economic models of selfdeception, such individuals will seek out, attend to, remember, and interpret evidence in ways that reinforce this belief [Bénabou and Tirole 2016].

According to the proposed account, some who suffer from imposter syndrome do so for the same reason that Jessica believes that her son is not smoking marijuana and Chris believes that his wife is having an affair-because the utility provided by those beliefs outweighs their disutility. Consequently — and in contrast to the family dynamics account-imposter syndrome is explained with reference to belief-based utility and the biases it produces. Not only does this explain the biased way in which people with imposter syndrome interpret evidence, it predicts that they will exhibit other forms of bias. For example, people with self-deceptive imposter syndrome may exhibit bias in the realms of evidence search and sampling, whereby they will predominately seek out, attend to, and recall evidence that supports their inadequacy beliefs (as described in the example of Sarah).

While this proposal provides one explanation for the behavioural element of imposter syndrome, it also illustrates how these practises qualify as motivated, as these individuals' own desire to succeed biases them towards the belief that they are inadequate, due to its motivational utility. Thus, the account illustrates how those who exhibit imposter syndrome may qualify as self-deceived, according to motivationalist accounts.

It is also consistent with stricter accounts of self-deception. For example, some philosophers hold that self-deception must not only be motivated but motivated by a desire to believe the relevant proposition [Nelkin 2002; Funkhouser 2005]. Crucially, 
these accounts do not insist that the self-deceived are aware of, or control, this desire. As Nelkin [2002: 395] writes, 'the desire to believe that $\mathrm{p}$ is true need not be conscious. It is likely not to be actively contemplated at the time during which the belief that $\mathrm{p}$ is formed, and it might even be difficult for an agent to recognize'. According to the proposed account of self-deceptive imposter syndrome, those who exhibit it unconsciously desire to believe in their own inadequacy, due to its motivational benefits.

Is this proposal consistent with intentionalism? Do those with self-deceptive imposter syndrome intend to deceive themselves into believing that they are inadequate? This depends on what one considers intention to entail. The biasing of our evidence treatment practises certainly appears purposive, as it guides our future selves towards beliefs with high utility [see Funkhouser 2019: 62]. If intentionalists are willing to concede that self-deception can occur as a relatively automatic and unconscious process (unlike most forms of intention), then the proposed model is consistent with intentionalism. Some intentionalists are willing to concede this possibility [Bermúdez, 2000], but at that point, one might argue that the line between motivationalism and intentionalism has become too blurry (see Funkhouser [2019: 67]).

I will not take a stand on which account of self-deception is correct, or most befitting of the above proposal. There are surprising difficulties in teasing apart different accounts of self-deception, and many philosophers point to the same processes as either being intentional or (non-intentionally) motivated [ibid.]. To adequately adjudicate the different issues at play here is beyond the scope of this paper.

I have argued for one particular form of self-deceptive imposter syndrome in this paper, but I leave open the possibility of alternative forms. While I have focused on the motivational utility derived from negative self-appraisal, there may be other, as of yet, 
underappreciated utility to such beliefs [Sharot and Sunstein 2020]. There may even be forms of self-deceptive imposter syndrome that are consistent with family dynamic accounts. Childhood experiences may directly result in the adoption of maladaptive reasoning styles, but they may also operate via the mechanisms of motivated reasoning, through instilling a desire to believe in one's own inadequacy. According to such an account, the relevant motivational biases would still need to be explained with reference to these experiences, rather than belief-based utility alone. ${ }^{7}$

Before concluding, I will briefly address a challenge sometimes pitched against belief-based utility accounts of self-deception [Pinker 2011]. ${ }^{8}$ The challenge, applied here, is to explain why people who desire success (in challenging and opaque domains) do not simply modify their behaviour, so as to exert as much effort as possible. Why would they self-deceive when this simpler route is available? In order to support my account, I need not answer this question. As discussed, research shows that some students focus on their lack of preparedness before exams and that some people with eating disorders focus on the 'fat' parts of their bodies. Crucially, both these groups claim that they engage in these practises in order to gain motivational benefits. So, people do engage in biased evidence treatment in order to motivate themselves. My argument is simply that self-deceptive imposter syndrome is another instance of this phenomenon; I need not also explain why this phenomenon occurs.

\section{Conclusion}

\footnotetext{
7 This would constitute a form of self-deception that is importantly different from the more commonly discussed varieties, introduced in section 3. Thanks to an anonymous reviewer for pointing out this possibility.

8 Thanks to Eric Funkhouser for bringing this argument to my attention.
} 
In this paper, I made progress on the task of explaining, defining, and evaluating imposter syndrome. I provided a novel explanation of a sub-class of imposter syndrome, as driven by the motivational utility provided by negative self-appraisal, within contexts where certain preconditions hold. This contrasts against psychological accounts that assume that the condition is maladaptive, resulting from problematic family dynamics. It also contrasts against contemporary philosophical accounts, which emphasize the role of epistemic obstacles, arising from social factors, as driving imposter syndrome [Hawley 2019b; Paul 2019; Slank 2019]. Nevertheless, I do not claim to contradict these accounts. As I have emphasized, imposter syndrome is a heterogenous phenomenon: different individuals exhibit it for different reasons, and different factors may drive it for the same individual. The proposed account opens the door for future research into how these different accounts connect and conflict.

How we identify the cause of imposter syndrome bears on how we define it. My argument shows that, within the category of imposter syndrome, we must make room for a self-deceptive variant. This identifies an unrecognised, yet remarkably widespread example of self-deception, one that many philosophers and psychologists have first-hand experience of. In turn, this opens the door for the use of first-hand experience as well as the literature on imposter syndrome to inform philosophical debates regarding selfdeception, helping to resolve some of the many disputes present in this literature.

One question for future research pertains to the prevalence of self-deceptive imposter syndrome: what proportion of those who suffer from imposter syndrome are self-deceived compared to, say, those who are acting out maladaptive behavioural patterns learnt during childhood. While this is an open question, I would note out that factors related to parenting style and family dynamics have only been found to weakly 
correlate with measures of imposter syndrome [Sakulku and Alexander 2011: 80-82]. In contrast, some preconditions I have stipulated as driving self-deceptive imposter syndrome (for example, perfectionism) highly correlate [ibid.: 86]. Given these findings, it may be the case that self-deceptive imposter syndrome is as common, if not more so, than forms of imposter syndrome that stem from problematic childhood experiences.

Finally, the proposed account introduces an important consideration for how we attempt to treat imposter syndrome. If imposter syndrome is underpinned by motivational bias, then motivations ought to be a target for treatment. This could be approached psychologically_by working with sufferers of imposter syndrome to reflect on and re-assess the utility provided by inadequacy beliefs_or situationally_by working to change the conditions that determine that utility.

However, we might also question whether imposter syndrome necessarily ought to be treated. In the psychological and philosophical literature, this point is undisputed; while researchers disagree on how imposter syndrome should be treated, they all assume that it should be. Yet, on the proposed account, there is significant value to the condition. ${ }^{9}$ Perhaps then, for those facing situations where the pathway to success is both challenging and opaque, but also considerably desirable, imposter syndrome is not something that should be treated. Perhaps such individuals should not seek to rid themselves of the relevant beliefs, but rather mitigate their affective disutility. Such a possibility is broached by Olberding [2018], who suggests that rather than trying to reject the imposter label, we simply embrace it, stripping it of the associated low self-esteem

\footnotetext{
${ }^{9}$ This is not to say that imposter syndrome is, overall, epistemically good, only that it has underappreciated benefits [see Bortolotti 2015].
} 
and fear of being exposed. ${ }^{10}$ After all, being a hard worker who does not rely on natural ability to succeed is an identity one ought to embrace, rather than be ashamed of. Perhaps those with self-deceptive imposter syndrome should strive for the state that Olberding now finds herself in:

'I sometimes still feel a fraud in academic environments, but neither do I mind it much'.

\section{Acknowledgments}

I would like to thank Simon van Baal, Tim Bayne, Andrew Corcoran, Manja Engel, Eric Funkhouser, Jakob Hohwy, Alex Kiefer, Andy McKilliam, Dan Williams, Iwan Williams, Jennifer Windt, and two anonymous reviewers for helpful discussion and/or written feedback on the manuscript.

\section{References}

Academic, Anonymous 2018. The path to professorship is long, rocky and confusing. Why? The Guardian. URL = <https://www.theguardian.com/higher-educationnetwork/2018/aug/24/the-path-to-professorship-is-long-rocky-and-confusingwhy $>$

Barnes, A. 1997. Seeing through self-deception, Cambridge: Cambridge University Press.

Bénabou, R. 2015. The economics of motivated beliefs. Revue d'économie politique, 125[5]: $665-685$.

Bénabou, R., and J. Tirole 2002. Self-confidence and personal motivation. The quarterly journal of economics, 117/3: 871-915.

\footnotetext{
${ }^{10}$ If psychologists are correct, and some of the motivational utility of imposter syndrome stems from the fear of being discovered (footnote 5), then this strategy may reduce motivational utility. Nevertheless, this may be an acceptable trade off, given the decrease in affective disutility.
} 
Bénabou, R., and J. Tirole 2016. Mindful economics: The production, consumption, and value of beliefs. Journal of Economic Perspectives, 30/3: 141-164.

Bermúdez, J. 2000. Self-deception, intentions, and contradictory beliefs. Analysis, 60/4: $309-319$.

Bortolotti, L. 2014. Irrationality, Malden, MA: John Wiley and Sons.

Bortolotti, L. 2015. The epistemic innocence of motivated delusions. Consciousness and cognition, 33: 490-499.

Bravata, D., S. Watts, S. A. Keefer, D. Madhusudhan, T. Taylor, D. Clark, R. Nelson, K. Cokley, and H. Hagg 2019. Prevalence, Predictors, and Treatment of Impostor Syndrome: a Systematic Review. Journal of General Internal Medicine, 35: 1-24.

Brocas, I., and J. D. Carrillo 2000. The value of information when preferences are dynamically inconsistent. European Economic Review, 44/4-6: 1104-1115.

Brunnermeier, M. K., and J. A. Parker 2005. Optimal expectations. American Economic Review, 95/4: 1092-1118.

Clance, P. R. 1985. The impostor phenomenon: Overcoming the fear that haunts your success, Atlanta, GA: Peachtree [kindle version]

Clance, P. R., and S.A. Imes 1978. The imposter phenomenon in high achieving women: Dynamics and therapeutic intervention. Psychotherapy: Theory, Research and Practice, 15/3: 241-247.

Clance, P. R., and M.A O’Toole 1987. The imposter phenomenon: An internal barrier to empowerment and achievement. Women and Therapy, 6/3: 51-64.

Clark, M., K. Vardeman, and S. Barba 2014. Perceived inadequacy: A study of the imposter phenomenon among college and research librarians. College and Research Libraries, 75/3: 255-271. 
Funkhouser, E. 2005. Do the self-deceived get what they want? Pacific Philosophical Quarterly, 86/3: 295-312.

Funkhouser, E. 2019. Self-Deception, London: Routledge.

Funkhouser, E., and D. Barrett 2016. Robust, unconscious self-deception: Strategic and flexible. Philosophical Psychology, 29/5: 682-696.

Gadsby, S. 2020. Self-deception and the second factor: How desire causes delusion in anorexia nervosa. Erkenntnis, 85/3: 609-626.

Golman, R., D. Hagmann, and G. Loewenstein 2017. Information avoidance. Journal of Economic Literature, 55/1: 96-135.

Harvey, J. C., and C. Katz 1985. If I'm so successful, why do I feel like a fake?: The impostor phenomenon, New York: St. Martin’s Press.

Hawley, K. 2019a. Conspiracy theories, impostor syndrome, and distrust. Philosophical Studies, 176/4: 969-980.

Hawley, K. 2019b. I-What Is Impostor Syndrome?. Aristotelian Society Supplementary Volume, 93/1: 203-226.

Kumar, S., and C.M Jagacinski 2006. Imposters have goals too: The imposter phenomenon and its relationship to achievement goal theory. Personality and Individual differences, 40/1: 147-157.

Langford, J., and P. R. Clance 1993. The imposter phenomenon: recent research findings regarding dynamics, personality and family patterns and their implications for treatment. Psychotherapy: theory, research, practice, training, 30/3: 495-501.

Leary, M. R., K. M. Patton, A. E. Orlando, and W. W. Wagoner 2000. The impostor phenomenon: Self-perceptions, reflected appraisals, and interpersonal strategies. Journal of personality, 68/4: 725-756. 
Leonhardt, M., M. N. Bechtoldt, and S. Rohrmann 2017. All impostors aren’t alikedifferentiating the impostor phenomenon. Frontiers in psychology, 8: 1505.

Lynch, K. 2012. On the 'tension' inherent in self-deception. Philosophical Psychology, 25/3: 433-450.

Mele, A. 2001. Self-deception unmasked, Princeton, NJ: Princeton University Press.

Nelkin, D. K. 2002. Self-deception, motivation, and the desire to believe. Pacific Philosophical Quarterly, 83/4: 384-406.

Norem, J. K., and N. Cantor 1986. Defensive pessimism: Harnessing anxiety as motivation. Journal of personality and social psychology, 51/6: 1208-1217.

Olberding, A. 2018. The Outsider. Aeon URL $=<$ https://aeon.com/essays/how-usefulis-impostor-syndrome-in-academia $>$

Paul, S. K. 2019. II—What Should 'Impostor Syndrome' Be? Aristotelian Society Supplementary Volume, 93/1: 227-245.

Pears, D. F. 1984. Motivated irrationality, New York, NY: Oxford University Press.

Pinker, S. 2011. Representations and decision rules in the theory of self-deception. Behavioral and Brain Sciences, 34/1: 35-37.

Sakulku, J., and J. Alexander 2011. The impostor phenomenon. The Journal of Behavioral Science, 6/1: 75-97.

Schubert, N., and A. Bowker 2019. Examining the impostor phenomenon in relation to self-esteem level and self-esteem instability. Current Psychology, 38/3: 749-755.

Schwitzgebel, E. 2002. A phenomenal, dispositional account of belief. Noûs, 36/2: 249_ 275.

Sharot, T., and C. R. Sunstein 2020. How people decide what they want to know. Nature Human Behaviour, 4: 14-19. 
Slank, S. 2019. Rethinking the Imposter Phenomenon. Ethical Theory and Moral Practice, 22/1: 205-218.

Taylor, M., B. Martin, and J. Wilsdon 2010. The scientific century: securing our future prosperity. The Royal Society. URL $=<$ https://royalsociety.org/topicspolicy/publications/2010/scientific-century/>

Taylor, S. E., and J. D. Brown 1988. Illusion and well-being: a social psychological perspective on mental health. Psychological bulletin, 103/2: 193-210.

Thompson, T. 2004. Failure-avoidance: Parenting, the achievement environment of the home and strategies for reduction. Learning and Instruction, 14/1: 3-26.

Van Leeuwen, D. N. 2007. The product of self-deception. Erkenntnis, 67/3: 419-437.

Yaffe, Y. 2020. Does self-esteem mediate the association between parenting styles and imposter feelings among female education students? Personality and Individual differences, 156: 109789. 